The establishment of the Sections as we now have stance in which a member, not of this Section, once them has prevented the Association from rapid de- put himself on the programme as prepared to present generation into a purely social excursion. A fur- a paper. When his turn came to read his essay and ther development of the plan, enabling the Sections his name was called, he was absent. In explanation to have more time and the general meetings of the of his failure to appear he said he had heard so Association, less time, will make it a scientific medi- many good papers read, superior to his own, that cal power in the country and in the world, and draw when his turn came he was ashamed to read his into its embrace the best workers in our profession essay. Hence one good result of presenting worthy throughout the United States. This will enable the papers is to keep out valueless articles. Men who Association to keep pace with other organjzations might have come to palm off poor stuff upon an unwhich have already made use of the Section-plan of organized assemblage, may remain to learn when work, with results in the character of their membership and quality of their published transactions, of which we as Americans should be proud, and which we as members of the American Medical Association should endeavor to obtain in our meetings. The American Medical Association will always possess the great advantage in meeting anually, thus enabling investigators to lay their results before a scientific body once a year.

So much for the application of the principle of Section work to the Association at large. What shall we say of, and for ourselves? This Section is four years old, having been created in 1888 . At the first meeting in Newport thirty-three papers were read, at its second meeting in Nashville, fourteen were read, at its third meeting, a year ago, in Washington only ten papers were read, though more were promised. This falling off was probably due to the illness of the chairman for that year. This year, as we are pleased to see, there are forty-four papers announced on the programme. The American Medical Association is the Charlemagne of the profession of medicine in this country; let this Section cherish the ambition of being its valiant and faithful Orlando.

Having been fortunate enough to succeed in obtaining the creation of Sections, and now having expressed the hope of gaining more time for Section work, by shortening the hours of the general sessions of the Association, it behooves us to go to work in earnest and make the existence of this Section of value to ourselves, and the profession. A direct and quick way of doing this is to prepare a paper, and attend the meeting and read it. The selection of papers deserving publication, their edition, and all matter pertaining to their publication should they increase greatly in number, night be left to a carefully chosen publication-committee. The discussions provoked by the papers read should be carefully reported by a stenographer, as they are generally as valuable as the essays.

Surely there is no channel in this country through which so large a number of physicians interested in Otology, Rhinology and Laryngology,can convey their views and the results of their labors to so large a number of intelligent hearers and readers as through this Section of the American Medical Association. Therefore, whoever is in earnest in his special work and in the desire and intention to communicate the results of his labors and have them discussed, and to learn from the writings and observations of others, should not fail to embrace the chance of doing these offered in this Section. Having obtained such an arena, from the parent Association, pride should prompt us to fill it with able contestants for the prizes sure to be gained by good scientific work. These are torn off by pieces, and the operation The presentation of good papers before any Section is more or less incomplete, leaving much to be done will tend to keep away bad ones. I know of an in-l by subsequent cauterization. For this purpose the 
chemical caustics are not suitable, for they either do not penetrate deep enough, or they must be used to such an extent that they spread beyond the area desired to be cauterized and do damage to the healthy parts.

By means of the galvano-cautery these growths may be reached at any point by bending the electrode to the desired shape. Small growths may be destroyed by a single puncture, and large ones by repeating the cauterization from time to time till they are entirely destroyed.

Large growths may be removed en masse by means of the galvano-cautery snare; small growths are not easily caught in the loop and are best destroyed by simply puncturing them with the galvano-cautery needle.

The galvano-cautery snare possesses several advantages over the forceps for the removal of large laryngeal growths. Its action is sure, quick, painless and bloodless. The stump is cauterized at the same time the growth is removed. The galvano cautery outfit for laryngeal work should consist of a one cell storage battery (or a suitable current controller if the street current is employed). Shech's handle, one half doz. electrodes (assorted), canula, fine wire, and connecting cables.

Everything should be in perfect working order before the throat is cocainized, as the effect of the cocaine soon passes off. With a well trained throat to operate on and everything in perfect working order, it is often impossible to reach the exact point desired, or to pass a loop over a tumor and get it properly adjusted, without a considerable loss of time. And my experience has been that when a throat is once irritated by the presence of an instrument it is not so readily controlled again that day.

The following case, of which the accompanying illustration is a faithful drawing, will illustrate the advantage of the cautery snare over the laryngeal forceps.

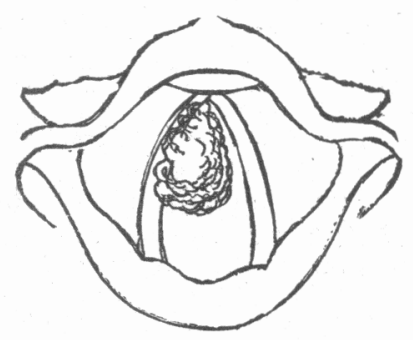

Laryngoscopic Image.-Papilloma, springing from the anterior two thirds of the right vocal cord.

Mrs. —, wt. 27 years, U.S. parentage, otherwise healthy, in possessing a full contralto voice, and very fond of music, suddenly lost her voice for singing; she could not sing anything. She thought she had "strained her voice." Months passed along and the voice grew more husky, and finally the trouble began to interfere materially with breathing and conversation. Upon examination a large papilloma was found springing from the anterior two-thirds of the right vocal cord, falling down between the cords. The throat was trained for some months, by passing the forceps down into the larynx and touching the growth, without cocaine. As soon as this could be done successfully, the next step was the selection of a suitable pair of forceps with which to remove the growth. Mackenzie's long forceps were half an inch too short, Mathieu's forceps were the right length, but were not large enough in the jaws to grasp the entire growth. (Specimen exhibited, preserved in alcohol.)

Next the galvano-cautery snare was tried and selected as the only means by which the growth could be removed en masse. The throat was thoroughly cocainized, a four per cent. spray was used for the pharynx, and a twenty per cent. solution applied to the larynx by means of an applicator. This was repeated three times at intervals of five minutes. After three or four trials the loop was properly adjusted so that the entire mass was engaged in the loop and quickly cut off. The throat was under perfect control, there was not the least pain experienced, and not a drop of blood lost Patient was instructed not to speak at all for four days, and not above a whisper for one week. Voice fully restored and no trace of any abnormality at the end of one year from date of operation.

In closing the discussion which followed the reading of the paper, the author explained the means employed to prevent the growths from falling into the trachea in case they should not adhere to the instrument. During the period of training the patients are instructed to take a full inspiration after the instrument is in position. The patients are not informed that the growth is to be removed at this sitting and the inspiration is taken as usual at the time the word is given. In case the growth should fall from the instrument when severed, it is at once expelled by the force of the cough which follows.

\section{A CASE OF TUBERCULOSIS OF THE PHARYNX.}

Read in the Section of Laryngology and Otology, at the Forty-third annual meeting of the American Medical Association, held in

\section{BY J. E. BOYLAN, M.D.,} OF cINCINNATI, OHIO.

PROFESSOR OF LARYNGOLOGY AND OTOLOGY, WOMEN'S MEDICAL COLLEGE, MEMBER OF THE STAFF OF THE PRESBYTERIAN
HOSPITAL, ETC.

Tuberculosis of the pharynx as a primary or local affection is of such exceptional occurrence and the nature of the affection so interesting, that I need hardly apologize for reporting a single case; my only regret in doing so, is that $I$ have not been able, since committing myself for this occasion, to review the literature so thoroughly as to be in a position to state exactly, the very short time within which each of the comparatively few cases recorded proved fatal or to enumerate the isolated ones reported to have recovered.

Mrs. B., of Carlisle, Ky., 25 years of age, six months pregnant, was brought by Dr. Ricketts, accompanied by her husband and brother, to consult with me concerning a very painful throat affection which had recently developed, and to establish, if possible, its exact nature.

The patient gave the following history: She had had a catarrhal condition of the throat for two years past which had been treated by her doctor at home with applications of nitrate of silver, but which made no progress towards recovery. About a year ago finding that she had an irritating cough, she consulted Dr. McKenzie, of Cincinnati, who informed her that she was threatened with consumption and recommended an immediate change of climate. During a six months' sojourn in the south, she had more than regained her former weight, the cough had left her and she returned some months ago believing her health entirely restored. Within the last six weeks, however, there had developed a painful condition of the throat, quite different from her former affection, which was rapidly growing worse. Although her appetite was good and she had no cough, she suffered so intensely at every attempt to swallow that she postponed taking food as long as possible, and begged for some speedy relief, so that she might again eat with comfort. Patient was fairly nourished, somewhat pale, there was noticeable enlargement of the cervical glands on both sides. Upon inspecting the pharynx the following characteristic picture presented itself :

General pallor of the mucous membrane of the hard palate was noticeable at a glance, which pallor comprised on the left side, the whole roof of the mouth as far back as the anterior pillar, while on the right side, it gradually 